\title{
Beyond Burnout: Responding to the COVID-19 Pandemic Challenges to Self-care
}

\author{
Richard F. Mollica ${ }^{1}$. Dinali B. Fernando ${ }^{2,3,4} \cdot$ Eugene F. Augusterfer ${ }^{5}$
}

(C) The Author(s), under exclusive licence to Springer Science+Business Media, LLC part of Springer Nature 2021, corrected publication 2021

\begin{abstract}
Purpose of Review This paper is a review of the self-care challenges of the COVID-19 pandemic on the physical and emotional health and well-being of healthcare providers. New self-care practices are presented.

Recent Findings Globally, thousands of health care practitioners and staff have been infected; many have died. Research studies reveal that this pandemic has threatened the health of healthcare staff, their families, and communities in many unique ways, such as fear of infecting family (lack of safety at home), moral injury, witnessing the suffering of the "innocent," coping with a problem too big to solve (the enormity problem), and racial trauma.

Summary The COVID-19 pandemic has impacted the global population in ways not seen in a century. The unique self-care challenges of COVID-19 while enhancing the symptoms of burnout, i.e., physical, and mental exhaustion, despair, helplessness, and suicidal thinking, need to be addressed directly. This paper offers a new COVID-19 self-care model and approach.
\end{abstract}

Keywords Self-care $\cdot$ Burnout $\cdot$ Suicide $\cdot$ Challenges $\cdot$ Moral injury $\cdot$ Enormity problem $\cdot$ Racial trauma $\cdot$ COVID-19

The self-care challenges of the COVID-19 pandemic are layered upon the pre-COVID challenges of burnout [1]. According to the Centers for Disease Control and Prevention (CDC), as of January 16, 2021, 365,072 healthcare workers have been infected with COVID-19, and 1254 have died in the

This article is part of the Topical Collection on Psychiatry in the Digital Age

Eugene F. Augusterfer

efa@gmhnet.com

Richard F. Mollica

rmollica@partners.org

Dinali B. Fernando

dinali.fernando@mssm.edu

1 Harvard Medical School, Massachusetts General Hospital, Boston, MA, USA

2 Department of Emergency Medicine, Icahn School of Medicine at Mount Sinai, New York, NY, USA

3 Department of Emergency Medicine, Elmhurst Hospital, Elmhurst, NY, USA

4 Libertas Center for Human Rights, Elmhurst Hospital, Elmhurst, NY, USA

5 Harvard Global Mental Health: Trauma and Recovery Program, Harvard Medical School, Boston, MA, USA
USA [2]. Amnesty International reports widespread healthcare worker deaths worldwide [3]. In Italy, for example, the Italian National Institute of Health documented COVID19-related deaths of 160 doctors, 40 nurses, and 2 suicides [4]. Early studies in the UK indicated that BAME (Black, Asian, or minority ethnic) healthcare workers appear to be significantly over-represented in the total number of COVID-19 deaths [5].

Before the pandemic, up to $50 \%$ of US physicians were experiencing professional burnout [6-8]. The Agency for Healthcare Research and Quality (AHRQ) defines burnout as a "long-term stress reaction marked by emotional exhaustion, depersonalization, and lack of a sense of personal accomplishment" [9]. Recently the WHO included burnout in the ICD-11 [10].

Within this pre-existing context of high burnout, the COVID-19 pandemic hit. Healthcare professionals at all levels rose above burnout to provide an extraordinary medical response, stepping forward to save lives at great cost to their own health and wellbeing. Healthcare workers in Scotland and their households, for example, accounted for $17.2 \%$ of all COVID-19-related hospital admissions, even though they represented only $11.2 \%$ of the working age population [11]. The profound toll of the COVID-19 pandemic on the physical and emotional state of healthcare staff necessitates that a new 
scientific self-care approach be urgently implemented that responds to the unique challenges of the COVID-19 pandemic affecting the health of clinicians.

\section{The Impact of COVID-19 on Family}

While healthcare workers constantly struggle with work-life balance, the issue of dual loyalty in caring for their families and patients has materialized in an unprecedented way during this pandemic. Enormous stress has been placed on healthcare workers' families [12].

This quote has been removed because it was inaccurate.

When both parents are frontline healthcare workers, they have had to implement measures should their children be orphaned [13]. Household members of healthcare workers are directly at risk for contracting the virus, with deleterious or even fatal outcomes, especially among elderly parents/grandparents. Not even in the military are family members put at such risk. Some healthcare workers have chosen to protect their families by living apart from them, despite the emotional toll of this separation. Dr. Christian Rose provides an illuminating description of his dilemma after his exposure to a COVID-19 patient:

I'm looking for a room where I can stay.... a no man's land where a colleague's spare bed may be the closest approximation to home we can find. [14]

Recent reports have revealed that household members of healthcare workers who cared for COVID-19 patients were nearly twice as likely to be admitted to hospital with COVID19 than other working age adults [11]. Unfortunately, there has been little research on the impact of burnout on medical families prior to COVID-19 to build upon $[15,16]$.

\section{Moral Injury}

Dean and Talbot have redefined burnout as moral injury [17, 18]. They posit that burnout is a symptom of a broken healthcare system. In contrast, the concept of moral injury, taken from military experience, means an injury caused by being involved in actions that transgress our deeply held moral beliefs. Dean and Talbot cite the journalist Diane Silver, who calls moral injury a "deep soul wound" that pierces a person's identity, sense of morality, and relationship to society [17]. Discovering an ethical and moral pathway for doctors and nurses during the COVID-19 crisis has been difficult, as they face terrible conflicts related to working without adequate personal protective equipment, deciding who receives a ventilator, being unable to protect patients from witnessing the resuscitation and passing of patients beside them, needing to limit family at the bedside of dying patients, and the constraints imposed on using culturally defined practices surrounding death and burial [19].

\section{The "Enormity Problem"}

As Bill Blakemore, noted $\mathrm{ABC}$ news correspondent has stated, the world is facing an "enormity problem," that is, a problem so big it is almost impossible to think about any solutions [20]. Lack of national leadership at every level during a time when we need it most is especially demoralizing [21]. This "enormity" analogy is applicable to the COVID-19 pandemic for several reasons.

\section{a) Suffering of the Innocent}

This pandemic is unlike any other disaster we have encountered in that we are in a "slow-moving mass casualty" [22]. The sheer magnitude of the suffering and death of innocent persons, without an end in sight, coupled with an as-yet inadequate understanding of the disease course and dearth of evidence-based treatment options, have left healthcare providers feeling overwhelmed and helpless. It is akin to the emotional despair well known to humanitarian workers serving mass populations impacted by war and ethnic conflict [23, 24]. When one of us first visited the refugee camp "site 2 " on the Thai-Cambodian border in 1988, he experienced for the first time the horrible suffering of tens of thousands of innocent Cambodian men, women, and children.

Images from the trauma stories I had heard that day flooded my mind... There was no way I could help them... There were too many people with too many traumatic life experiences living in too terrible poverty and confinement. [23]

\section{b) Destruction of the Natural World}

The ecocide of our natural world has added to the complexity of curbing this pandemic. The medical concept of One Health brings hope that the root causes of such pandemics can be prevented. One Health is a multisectoral and transdisciplinary medical approach working at all policy levels, with the goal of achieving optimal health outcomes by fostering positive health linkages between people, plants, animals, and their shared environments [25].

\section{Racial Trauma}

The challenges of the COVID-19 pandemic have been exacerbated by racial trauma [26••]. The severe social 
inequities and health disparities among communities of color have been brought to the forefront by the disproportionate impact of COVID-19 on Black, Latino, and Indigenous American populations. Without national systemic efforts to address the social determinants of health, healthcare workers are left without the tools to effectively care for their minority patients and vulnerable populations. An example is having to discharge a patient with instructions to quarantine when the patient lives in an overcrowded situation without the ability to isolate. Studies in the USA [27], Sweden [28], and Britain have revealed that migrants, Black persons, ethnic minorities, and Asians, respectively, have been disproportionately infected by the COVID-19 pandemic [29•]. Racial trauma has emerged as a major chief complaint among healthcare staff of color [26*•]. Despite hours caring for critically ill COVID-19 patients, Asian American healthcare workers have been accused of causing the pandemic, called racial epithets and even physically assaulted.

The physical and mental exhaustion associated with these challenges cannot be meaningfully captured by the term "burnout." With the entire medical profession experiencing collective trauma, medicine is at a selfcare turning point. The medical system's anemic prepandemic response to burnout, such as dinners for doctors and relaxation classes, while helpful, were not sufficient to aid health practitioners in dealing with the intense exhaustion and pain caused by the large-scale human suffering of the COVID-19 pandemic [30•]. New self-care instruments and practices necessary to meet these challenges are offered by the authors (www.HPRTselfcare.org). These instruments have been translated into Italian and widely disseminated in Italy during the recent crisis (www.intraumacenter.com). Healthcare systems need to move beyond burnout through sustainable change targeting the root causes of pandemic distress [31]. Only by doing so can we heal the damage done by COVID-19 to healthcare workers and revitalize the ideals and spirit of medical practice.

\section{References}

Papers of particular interest, published recently, have been highlighted as:

- Of importance

•- Of major importance

1. Yates SW. Physician stress and burnout. Am J Med. 2020;133:160-4.

2. https://covid.cdc.gov/covid-data-tracker/\#health-care-personnel Accessed 16 Jan 2021.
3. Amnesty International, Health workers globally are silenced, exposed and attacked, 2020.

4. Istituto Superiore di Sanita. Infografica 25 May ITA.

5. Marsh S, McIntyre N. Six in 10 UK health workers killed by COVID-19 are BAME, The Guardian 2020. https://www. theguardian.com/world/2020/may/25/six-in-10-uk-health-workerskilled-by-covid-19-are-bame. Accessed July - September 2020.

6. Linzer M, Manwell LB, Mundt M, et al. Organizational climate, stress, and error in primary care: the MEMO study. In: Henriksen K, Battles JB, Marks ES, et al., editors. Advances in patient safety: from research to implementation (Volume 1: Research Findings). Rockville (MD): Agency for Healthcare Research and Quality (US); 2005.

7. Shanafelt TD, Boone S, Tan L, Dyrbye LN, Sotile W, Satele D, et al. Burnout and satisfaction with work-life balance among US physicians relative to the general US population. Arch Intern Med. 2012;172:1377-85.

8. Shanafelt TD, Hasan O, Dyrbye LN, Sinsky C, Satele D, Sloan J, et al. Changes in burnout and satisfaction with work-life balance between 2011 and 2014. Mayo Clin Proc. 2015;90:1600-13.

9. Physician Burnout. Agency for healthcare research and quality, Rockville, MD. https://www.ahrq.gov/prevention/clinician/ahrqworks/burnout/index.html. Accessed July - September 2020.

10. World Health Organization. Burn-out an "occupational phenomenon": International Classifications of Diseases. https://www.who. int/mental health/evidence/burn-out/en/

11. Shah ASV, Wood R, Gribben C, Caldwell D, Bishop J, Weir A, et al. Risk of hospital admission with coronavirus disease 2019 in healthcare workers and their households: nationwide linkage cohort study. BMJ. 2020. https://doi.org/10.1136/bmj.m3582.

12. Mnookin S. I cried in private: the stress of being a doctor and parent working in a COVID-19 unit: Boston Globe Magazine; 2020.

13. Drucker J. Two E.R. workers worry: if they died, who'd take care of their son? New York Times. 2020. https://www.nytimes.com/2020/ 04/20/nyregion/er-workers-hospitals-coronavirus.html Accessed July - September 2020

14. Rose C, Am I. Part of the cure or am I part of the disease? Keeping coronavirus out when a doctor comes home. N Engl J Med. 2020;382:1684-5.

15. Berg S. How doctors can keep their families safe after providing COVID-19 care. AMA-assn.org. 2020.

16. Gabbard GO, Menninger RW, Coyne L. Sources of conflict in the medical marriage. Am J Psychiatry. 1987;144:567-72.

17. Talbot SG, Dean W. Physicians aren't 'burning out.' They're suffering from moral injury https://www.statnews.com/2018/07/26.

18. Dean W, Talbot S, Dean A. Reframing clinician distress: moral injury not burnout. Fed Pract. 2019;36:400-2.

19. Ofri D. The public was forgiving. But hospitals got some things wrong. New York Times. 2020.

20. Blakemore W. Oral presentation, Orvieto, Italy, 2016.

21. Dying in a Leadership Vacuum. N Engl J Med 2020; 383:14791480. https://doi.org/10.1056/NEJMe2029812.

22. Strayer R A mass casualty in slow motion: emergency medicine during the COVID-19 surge in New York City. $2020 \mathrm{https} / /$ emupdates.com/surge/. Accessed July - September 2020.

23. Mollica RF. Healing invisible wounds, page 21, 2006. Nashville: Vanderbilt University Press.

24. Suarez-Orozco, editor. Humanitarianism and mass migration: confronting the world crisis. Oakland, CA: University of California Press; 2019.

25. https://www.cdc.gov/onehealth/. Accessed July - September 2020.

26.• Mollica RF, Fernando D. When racial trauma is a chief complaint among health-care staff. Lancet, Correspondence. 2020. This paper explores the racial inequities witnessed in the COVID-19 
pandemic, including the racial trauma suffered by health-care staff of color.

27. Tai DBG, Shah A, Doubeni CA, Sia IS, Wieland ML. The disproportionate impact of COVID-19 on racial and ethnic minorities in the United States. Clin Infect Dis. 2020.

28. Valeriani G, Vukovic IS, Mollica RF. Unconventional answers to unprecedented challenges: the Swedish experience during the COVID-19 outbreak. J Prev Med Public Health. 2020;53(4):233-5.

29. Abuelgasim E, Saw LJ, Shirke M, Zeinah M, Harky A. COVID-19: unique public health issues facing Black, Asian, and minority ethnic communities. Curr Probl Cardiol. 2020;45(8). This study documents the inequities faced by Black, Asian, and minority ethnic communities in the UK during the COVID-19 pandemic.
30. Hartzband P, Groopman J. Physician burnout, interrupted. N Engl J Med. 2020;382:2485-7. This study indicates a new and innovative approach to physician burnout as offered in this article.

31. Shapiro J, McDonald TB. Supporting clinicians during Covid-19 and beyond - learning from the past failures and envisioning new strategies. N Engl J Med, Perspective. 2020.

Publisher's Note Springer Nature remains neutral with regard to jurisdictional claims in published maps and institutional affiliations. 